The Fundamental Conditions of Surgical Shock. I4I

It seems that the anemic condition always observed in the skin in shock is also found in the organs generally. Further experiments are being performed to ascertain the location of the blood.

\title{
89 (499)
}

The fundamental conditions of surgical shock.

\section{BY YANDELL HENDERSON.}

[From the Physiological Laboratory of the Yale Medical School.]

Death in shock may be either from failure of respiration, or from failure of the circulation. In Crile's experiments, and in my own, the former mode of death was much more common than the latter. As I have recently shown, deaths of this type occur also in human beings after intense pain. The excessive breathing induced by pain diminishes the carbon dioxide content of the blood and tissues. This acapnia is the cause of the depression of all functions so characteristic of shock. Finally, apnœa vera occurs in exactly the same manner as in a normal man after voluntarily forced breathing.

If death from apncea is prevented by supplying artificial respiration, as in the majority of Crile's experiments, or by continual afferent irritation, as in my own, the circulation fails. Crile proved that this is not heart failure. Seelig and Lyon have proved that it is not vaso-motor failure, but that on the contrary the peripheral arteries are in intense constriction. Malcolm has suggested that the volume of the blood is diminished because of a passage of serum into the tissues. Sherrington and Copeman observed a considerable increase in the specific gravity of the blood even before arterial pressure had fallen to a low level. The balance between the water content of the blood and of the tissues is probably in part dependent upon their relative carbon dioxide contents. Acapnia may alter the tonus of the veins, or the relative osmotic pressure of the blood and the tissue fluids, or the imbibition tension of the colloids of blood and tissues. Thus acapnia diminishes the volume of the blood.

I find that acapnia induced by excessive artificial respiration, or by excessive natural breathing during stimulation of afferent nerves (i. e., trauma), involves a lowered venous pressure and 
diminished diastolic filling of the heart. This condition I would call acapnial oligæmia, or exsanguinity. It is compensated temporarily by constriction of the arterioles. The blood stream diminishes until finally it is insufficient to supply the oxygen needed by the tissues. Then tissue asphyxia, and acute acidosis quickly result. The colloids of the tissues in asphyxial acidosis imbibe water in the same manner as does fibrin when soaked in dilute acid. The vascular system is thus emptied as if by hemorrhage. Fluid passes from the blood into the tissues almost as fast as it can be supplied by intra-venous infusion of saline.

Thus there are two sequences: (I) pain-hyperpnœa, acapnia, and fatal apnœa vera, $i$. e., failure of respiration; (2) pain-hyperpnœa, acapnial oligæmia, and cyto-asphyxial oligæmia, i. e., failure of the circulation because of exsanguinity.

A full discussion of this topic and its literature will soon be published in the American Journal of Physiology.

$$
90(500)
$$

\section{Observations on the nature of the antitrypsin of the serum.}

\section{By R. WeIL and S. FELDSTEIN.}

\section{[From the Department of Experimental Therapeutics, Cornell University Medical School, New York.]}

In a previous communication to this society, it was shown by the authors that the viscosimeter offers a method for determining the anti-tryptic activity of serum which is extremely accurate, delicate and constant in its results. Further study by means of this method has revealed the fact that this so-called anti-tryptic activity is in reality very much more complex than had hitherto been suspected. If a series of intracellular enzymes are prepared from various human organs and from carcinomata, according to the method of Wiechowski, by drying, it becomes possible to test the inhibitory action of any given serum against each of these enzymes by the use of the viscosimeter. This has been done by the authors with a considerable number of sera. The resulting figures, which have been constant in successive experiments, demonstrate that the inhibitory value of each serum is distinct and different for each of the enzymes tested. These differences are extreme, inasmuch 